\title{
The Mediating Role of Internet Addiction Tendencies on the Relationship Between Loneliness and Emergence of Insomnia Tendencies Among Adolescents in Makassar During the Pandemic Period
}

\author{
Grestin Sandy ${ }^{1 *}$, Andi Alya ${ }^{2}$, Mayenrisari Arifin ${ }^{3}$ \\ ${ }^{1}$ Psychology Department of Medical Faculty, Hasanuddin University \\ ${ }^{2}$ Psychology Department of Medical Faculty, Hasanuddin University \\ ${ }^{3}$ Psychology Department of Medical Faculty, Hasanuddin University \\ *Corresponding author. Email: grestin.sandy@unhas.ac.id
}

\begin{abstract}
Teenagers are limited in interacting directly with their peers during the pandemic. This situation makes teenagers become lonely and use the internet more. Insomnia has also increased during the pandemic. This study aims to: (1) determine the direct influence of loneliness on the emergence of insomnia tendencies in adolescents in Makassar City during the pandemic; and 2) determine the contribution of internet addiction tendencies as a mediator of the influence of loneliness on the emergence of insomnia tendencies. Respondents in this study were adolescents aged 15-19 years, domiciled in Makassar City, and felt alienated from the surrounding environment or felt alone. This study used the purposive sampling technique and obtained a total of 331 respondents. The measuring instruments used are UCLA Loneliness Scale Version 3 (20 items, $\alpha=0.824$ ), Insomnia Severity Index (7 items, $\alpha=0.997$ ), and Internet Addiction Test (20 items, $\alpha=0.895$ ). Data were analyzed using a regression test with path analysis. The results showed that: (1) there was no direct effect of loneliness on the emergence of insomnia tendencies in adolescents in Makassar City during the pandemic; (2) there is a mediating effect of internet addiction tendencies on the influence of loneliness on the emergence of insomnia tendencies in adolescents in Makassar City during the pandemic. This study implies the importance of internet use management skills for adolescent during Pandemic.
\end{abstract}

Keywords: Loneliness, insomnia tendency, internet addiction tendency, teenagers, pandemic.

\section{INTRODUCTION}

The pandemic situation has a psychosocial impact on all individuals, as well as for teenagers. Restricting social activities limits the space for teenagers and causes psychosocial consequences. The psychosocial effects caused vary from depression, anxiety, loneliness, changes in sleep patterns, etc. Adolescents who experience loneliness are vulnerable to physical and social isolation so that it can make adolescents have little experience of social contact with other people [1].

Most teenagers experience loneliness [2]. There are $70 \%$ of adolescents experience loneliness, especially at the age of 18 years [3]. Likewise, the survey results found that $73 \%$ of Generation $\mathrm{Z}$ (born 1996-2010) always felt lonely[4]. This happens because of the inability of adolescents to cope with social change and not being able to get the social relationships they expect [5]. Loneliness is a negative feeling that occurs when individuals feel deprived and dissatisfied with their social relationships, both quantity and quality [6].

Loneliness is highly correlated with the onset of sleep disorders, especially sleep quality disorders and insomnia symptoms [7]. This is also reinforced by another research that found that lonely individuals are more likely to experience non-restorative sleep even when the sleep duration is the same as individuals who 
are not lonely, so lonely individuals tend to experience daytime dysfunction, which is greater than that of nonloneliness individuals [8].

The emergence of loneliness makes teenagers do activities that aim to eliminate these unpleasant feelings. One of these activities is spending time playing on the internet. Spending time playing on the internet is one of the defense mechanisms or coping strategies that teenagers constantly carry out to deal with the loneliness problems they experience. Teenagers tend to use the internet as an 'escape' is because they can get opportunities to reduce loneliness by building social relationships with people they meet online. In addition, adolescents can communicate riskfree with others, express thoughts and feelings freely, only show the identity they want to offer, and relate at any time [9]. Various advantages and conveniences obtained through the internet make teenagers use and spend more time on the internet. However, this increased use can lead to addiction [10].

The results of other studies that strengthen the relationship between internet addiction and sleep disorders, especially insomnia, states that pathological or excessive internet use is related to low quality sleep and the incidence of subjective insomnia [11]. Insomnia can be classified into two groups, namely primary insomnia and secondary insomnia. Health problems or accompanying psychological disorders do not cause primary insomnia. This insomnia is usually related to bedtime habits, individual sleep patterns, or the bed environment. In comparison, secondary insomnia is insomnia that arises due to medical, neurological, psychological/mental problems, and drug/alcohol dependence [12]. Therefore, in the case of individuals who experience internet addiction and cause sleep disorders, it can be classified that these individuals tend to experience primary insomnia because there is no accompanying medical, psychological, or drug dependence problems.

Insomnia, both primary and secondary, harms the daily lives of individuals who experience it. The destructive impact of insomnia is that individuals will feel tired, have mood disorders, increase complaints about physical pain, decrease individual quality of life, and decrease cognitive performance. In addition, insomnia can make individuals feel unrefreshed when they wake up and feel sleepy during the day but still cannot fall asleep. Finally, insomnia can also impact the individual's daily performance and decrease work productivity [13]. Therefore, this study intends to further examine whether loneliness directly affects the emergence of insomnia or through the mediating variable of internet addiction tendencies during the pandemic period.

\section{METHOD}

\subsection{Participant}

The population in this study is teenagers who live in Makassar with an age range of 15-19 years, which is based on a projected number of around 789,400 in 2020. Calculation of the sample size obtained a minimum sample size of 331 people. The sampling technique in this study used a purposive sampling technique with the following criteria, adolescents aged 15-19 years, living in Makassar City, and feeling alienated from the surrounding environment or feeling alone.

\subsection{Measurement}

\subsubsection{Dependent Variable}

The tendency of insomnia referred to in this study is the tendency of individuals (in this case adolescents) to experience sleep disorders which are characterized by difficulty in initiating sleep and maintaining sleep, as well as difficulty in getting quality sleep, which ultimately causes feelings of being unrefreshed and tired the next day thus affecting the individual in the activity. Operationally, the tendency of insomnia is the total score of the Insomnia Severity Index (ISI). Insomnia Severity Index (ISI) has been adapted into Indonesian [14]. The Cronbach alpha value on this scale is 0.997 , which means this scale is reliable for measuring insomnia.

\subsubsection{Independent Variable}

Loneliness in this study is an individual's subjective feelings and unpleasant experiences caused by a lack of social relationships, both quantitatively (having few friends) and qualitatively (lack of intimacy or attachment to others), which ultimately lead to negative feelings of the community. Individuals include unhappiness, boredom, restlessness, anxiety, or depression. In addition, loneliness is the total score of the UCLA Loneliness Scale version 3. UCLA Loneliness scale version 3 has been adapted into the Indonesian version [15]. This scale has a Cronbach alpha value of 0.824 , which means that this scale is reliable for measuring loneliness. 


\subsubsection{Mediator Variable}

The tendency of internet addiction referred to in this study is the tendency of individuals (in this case adolescents) to experience interference or dependence in the use of the internet, which is addictive and destructive. Characterized by the individual's inability to control time using the internet, increasing internet use, feeling the virtual world is more comfortable and interesting than the real world, using the internet for things that are not important and using it as a psychological escape, thus having a negative impact on other parts of the individual body life. The trend of internet addiction can be seen from the total score of the Internet Addiction Test (IAT). Internet Addiction Test (IAT) has been adapted into Indonesian [16]. The Cronbach alpha value on this scale is 0.895 , which means this scale is reliable for measuring internet addiction.

\subsection{Statistical Analysis}

The hypothesis in this study was tested using a regression test with path analysis. Regression analysis or test is a statistical method for estimating the relationship between the dependent variable and independent variables. Path analysis is an extension of multiple regression analysis. This analysis is used when in research there is a mediating variable in it. Therefore, path analysis aims to see the relationship between variables, either directly or indirectly [17].

\section{RESULT}

\subsection{Assumption Test}

\subsubsection{Normality Test}

The significance value of the normality test by One-Sample Kolmogorov-Smirnov carried out is 0.200 . The value is greater than 0.05 . Therefore, it can be assumed that the residual data are normal.

\subsubsection{Linearity Test}

The linearity value from the test of linearity test for insomnia and loneliness tendencies variable is 0.007 . The value is smaller than 0.05. In addition, the deviation from linearity value obtained is 0.107 . The value is greater than 0.05 . Because both assumptions are met, it can be assumed that the two variables have a linear relationship. The linearity value of the linearity test for insomnia and internet addiction variables is 0.000 . The value is smaller than 0.05 . The deviation from linearity value obtained is 0.869 . The value is greater than 0.05 . Because both assumptions are met, it can be assumed that the two variables have a linear relationship.

\subsubsection{Multicollinearity Test}

The tolerance value obtained from the loneliness and internet addiction tendency variables from the multicollinearity test results is 0.937 . The value is greater than 0.10. In addition, the value of VIF (Variance Inflation Factor) obtained by the two variables is 1.067. The value is less than 10.00 . Because both assumptions are met, it can be assumed that there is no multicollinearity in the regression model that will be used.

\subsubsection{Heteroscedasticity Test}

The significance value obtained by the loneliness variable from the results of the heteroscedasticity test on the absolute value of the residue is 0.498 . The value is greater than 0.05 . Similarly, the internet addiction trend variable has a significance value of 0.196 . This value is also greater than 0.05 . Therefore, it can be assumed that there is no heteroscedasticity symptom in the regression model that will be used.

\subsection{Hypothesis Testing}

Research hypotheses were tested using multiple regression tests through path analysis. The hypotheses in this study are as follows:

\section{First Hypothesis:}

$\mathrm{H}^{0}$ : There is no direct influence of loneliness on the tendency of insomnia in adolescents in Makassar City during the pandemic period.

$\mathrm{H}^{1}$ : There is a direct influence of loneliness on the tendency of insomnia in adolescents in Makassar City during the pandemic period.

\section{Second Hypothesis:}

$\mathrm{H}^{0}$ : There is no mediating effect of internet addiction tendencies on the influence of loneliness on the emergence of insomnia tendencies in adolescents in Makassar City during the pandemic period.

$\mathrm{H}^{1}$ : There is a mediating effect of internet addiction tendencies on the influence of loneliness on the emergence of insomnia tendencies in adolescents in Makassar City during the pandemic period. 


\subsubsection{Path Analysis Model I}

Table 1. Analysis result of effect loneliness on internet addition tendency

\begin{tabular}{cccc}
$\mathbf{R}$ & $\begin{array}{c}\mathbf{R} \\
\text { Square }\end{array}$ & $\begin{array}{c}\text { Adjusted } \mathbf{R} \\
\text { Square }\end{array}$ & $\begin{array}{c}\text { Std. Error of the } \\
\text { Estimate }\end{array}$ \\
\hline $0,251^{\mathrm{a}}$ & 0,063 & 0,060 & 11,18642 \\
\hline
\end{tabular}

Based on Table 1, it can be seen that the standardized coefficients of the loneliness variable on the internet addiction tendency variable are 0.251 . The standardized coefficients value shows the path coefficient a (regression coefficient from loneliness to internet addiction tendencies). In addition, the table above also shows a significance value of 0.000 . The value is smaller than 0.05 . Thus, it can be said that loneliness significantly affects the tendency of internet addiction. With an $\mathrm{R}$ Square $\left(\mathrm{R}^{2}\right)$ value of 0.063 , it shows that the contribution of loneliness to internet addiction is $6.3 \%$, while the rest is influenced by other variables not examined (Table 2).

\subsubsection{Path Analysis Model II}

Based on Table 2, it can be seen that the value of the standardized coefficient of the loneliness variable on the insomnia tendency variable is 0.062 . The value of the standardized coefficients shows the path coefficient value $c^{\prime}$ (direct influence and also the regression coefficient of loneliness variable to insomnia tendency by controlling for insomnia tendency variable). In addition, table II also shows the value of the standardized coefficients of the internet addiction tendency variable on the insomnia tendency variable of 0.335 . The value of standardized coefficients shows the path coefficient value $b$ (regression coefficient of the internet addiction tendency variable to the tendency of insomnia by controlling for loneliness variable).

Table 2. The value of the standardized coefficient of the loneliness variable

\begin{tabular}{|c|c|c|c|c|c|}
\hline \multirow[t]{2}{*}{ Variable } & \multicolumn{2}{|c|}{ Unstandardized Coefficients } & Standardized & \multirow{2}{*}{$t$} & \multirow{2}{*}{ Sig } \\
\hline & B & Std. Error & Beta & & \\
\hline Loneliness & 0,061 & 0,053 & 0,062 & 1,163 & 0,246 \\
\hline $\begin{array}{l}\text { Internet Addiction } \\
\text { Tendency }\end{array}$ & 0,156 & 0,025 & 0,335 & 6,276 & 0,000 \\
\hline
\end{tabular}

\section{Dependent Variable: Insomnia Tendency}

Table 2 also shows the significant value of the loneliness variable to the insomnia tendency of 0.246 . The value is more significant than 0.05 . Meanwhile, the significance value of the internet addiction tendency variable to the insomnia tendency is 0.000 . The value is smaller than 0.05 .

Thus, it can be said that the tendency of internet addiction significantly affects the tendency of insomnia, and loneliness does not affect the tendency of insomnia. $\mathrm{R}$ Square $\left(\mathrm{R}^{2}\right)$ value of 0.126 shows the contribution of the influence of loneliness and the tendency of internet addiction to the tendency of insomnia $12.6 \%$, while the rest is influenced by other variables not examined (Table 3 and 4).

Table 3. Influence of other variables not examined.

\begin{tabular}{cccc}
$\mathbf{R}$ & $\begin{array}{c}\mathbf{R} \\
\text { Square }\end{array}$ & $\begin{array}{c}\text { Adjusted } \mathbf{R} \\
\text { Square }\end{array}$ & $\begin{array}{c}\text { Std. Error of the } \\
\text { Estimate }\end{array}$ \\
\hline $0,355^{\mathrm{a}}$ & 0,126 & 0,121 & 5,05655 \\
\hline
\end{tabular}


Table 4. Influence of other variables not examined (2)

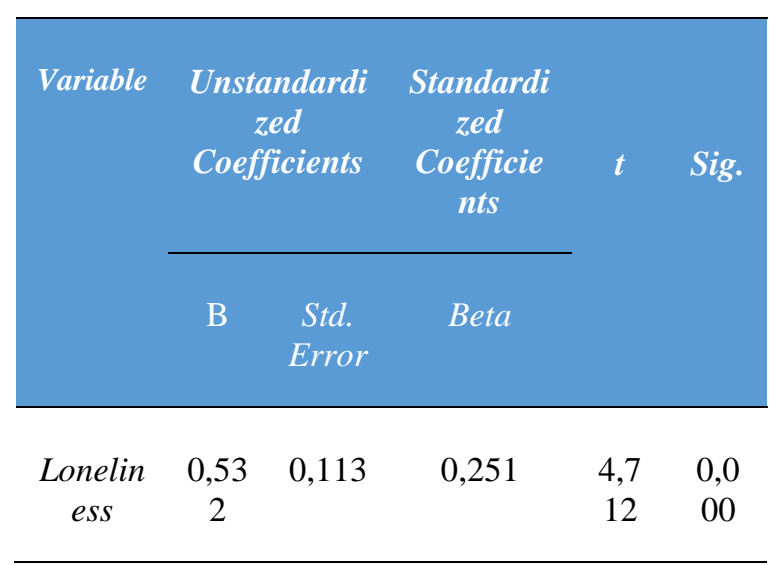

The first hypothesis in this study that there is no direct influence of loneliness on the tendency of insomnia in adolescents in Makassar City during the pandemic period is accepted. The second hypothesis in this study that there is a mediating effect of interest addiction tendencies on the influence of loneliness on the emergence of insomnia tendencies in adolescents in Makassar City during the pandemic period is accepted too. This can be seen from the comparison of direct effects, indirect effects, total effects, and the Sobel test scores below:
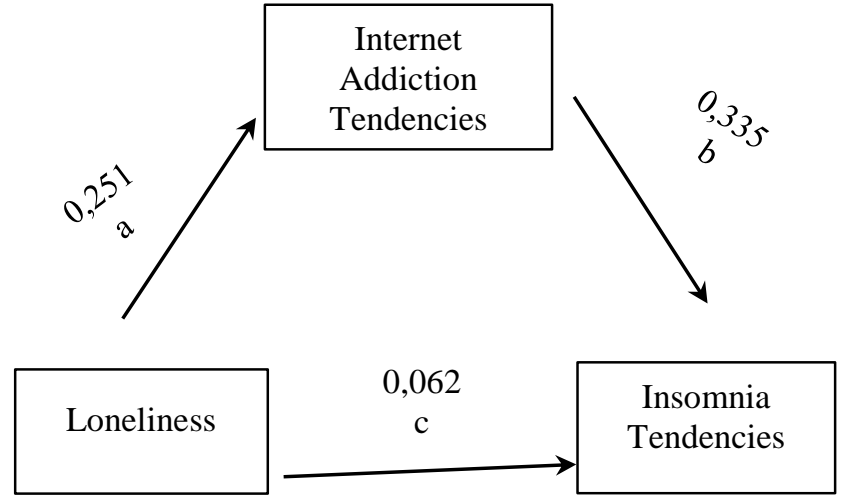

Figure 1. Role of the loneliness variable on the insomnia tendency

The direct effect or role of the loneliness variable on the insomnia tendency variable can be seen from the path coefficient value c, which is 0.062 . Meanwhile, the indirect effect of loneliness on the tendency of insomnia is obtained from the multiplication of path coefficient values $a$ and $b$, namely $(0.251)(0.335)=0.084$. From this value, it can be seen that the direct effect value is smaller than the indirect effect value $(0.062<0.084)$, so it can be said that the internet addiction tendency variable can mediate the relationship between loneliness and insomnia tendency.
The effect value or the total role of the loneliness variable is obtained from the sum of the direct effects plus indirect effects, namely $0.062+0.084=0.146$. From this value, it can also be seen that the portion of the indirect effect is greater than the direct effect. Therefore, it can be said that the mediator variable (internet addiction tendency) plays an effective role in mediating the relationship between the independent variable (loneliness) and the dependent variable (insomnia tendency).

In addition, the role of the mediator variable can also be seen through the significance of its indirect effect. One way that can be done to test the significance and see the value of the indirect effect is to use the Sobel test. The Sobel test was carried out using the Sobel test calculator, which was accessed online through the quantpsy.org page. The results of the statistical test scores obtained from the Sobel test were $3.7681>1.96$, and the $p$-value was $0.000164<$ 0.01 . Therefore, it can be concluded that the internet addiction tendency significantly mediates the relationship between loneliness and insomnia tendency.

Thus, from the existing research results, it can be concluded that loneliness does not affect the emergence of insomnia tendencies in adolescents in Makassar City. However, loneliness can affect the emergence of insomnia tendencies in adolescents in Makassar City when mediated by the internet addiction tendency variable. Therefore, it can be said that loneliness can affect the emergence of insomnia tendencies in adolescents in Makassar City only if other variables mediate the relationship between the two variables.

\section{DISCUSSION}

The tendency of internet addiction to mediate the influence of loneliness on the emergence of insomnia tendencies is that individuals who experience the loneliness like to spend their free time in solitary activities, one of which is playing gadgets [18]. Individuals who experience loneliness use the internet as a means of "escape" from the problems they experience, especially to eliminate negative and unpleasant feelings they experience, namely feelings of loneliness, both emotionally and socially. Spending time on the internet is one of the defense mechanisms or coping strategies that are constantly being used to deal with loneliness problems experienced by teenagers [9]. 
In addition, the existence of life events can also be one factor that makes the tendency of internet addiction significantly mediate the influence of loneliness on the emergence of insomnia tendencies. This is because individuals who are dissatisfied or disappointed with particular areas or areas of their lives and lack intimacy or strong relationships with other people will have a greater chance of developing internet addiction. After all, they do not understand different ways to overcome them ${ }^{[19]}$. Therefore, starting from the dissatisfaction and lack of intimacy with other people, individuals look for ways to overcome it. It is by accessing the internet, which can eventually develop excessive internet use or addiction.

In addition, during the current COVID-19 pandemic, there was concern that social distancing would lead to increased loneliness [20]. However, it was found that there was no increase in loneliness even though quarantine was carried out, compared to loneliness before the pandemic. This can happen because individuals, families, and communities can still connect emotionally even though they are far apart. One of them is thanks to the development of technology that has bridged many people to communicate with each other [21]. Although it was associated with quarantine and orders to stay at home, the impact of COVID-19 was negatively associated with loneliness, but it was more influential on the emergence of health anxiety and financial worry[22]. This study found the importance of social connection to reduce the negative psychological effects of the COVID-19 pandemic.

Based on this, it can be said that there is no difference in loneliness in adolescents during the pandemic and before the pandemic. However, it was found that the level of adolescent loneliness during the pandemic was in a fairly high category, with a percentage of $43 \%[24]$. This happens because teenagers can still communicate, socialize, and get support from others through the help of social media. Screen time for children and adolescents increased by $71.7 \%$ during the pandemic ${ }^{[24]}$. Individual online duration in Indonesia increased by $52 \%$ compared to before the pandemic [25]. But physical distancing does not increase the risk of internet addiction, but rather an increase in the duration of daily online activities and virtual socialization. Adolescents in various parts of the world increase the duration of using social media contacts, such as Instagram, Snapchat, and TikTok to stay in touch with other people and their peers [26].
The increasing use of electronic media and the internet raises other problems, namely increasing the possibility of adolescents experiencing sleep disorders in terms of quality, quantity, and experiencing insomnia problems. The prevalence of sleep disorders in adolescents during the COVID-19 pandemic was very high [27]. This is because there is a relationship between screen time and sleep disturbances in adolescents during the COVID-19 pandemic. Likewise, these results found that the prevalence of insomnia symptoms in adolescents (high school students) and early adults (students) in China was higher during the COVID pandemic. -19 , which is $23.2 \%$ [28]. One of the factors is poor sleep habits, such as staying up late due to increased use of mobile phones, playing online games, and shopping online, resulting in decreased sleep hygiene and sleep quality, prolonged sleep latency, and shorter sleep times. Based on the explanation above, it further strengthens the results of this study that the tendency of internet addiction can mediate the influence of loneliness on the emergence of insomnia tendencies in adolescents, especially in Makassar City.

\section{CONCLUSION}

The study found internet addiction tendency mediates the effect of loneliness and the emergence of insomnia tendencies among adolescents in Makassar City during Pandemic. This study implies the urgency of the intervention related to internet consumption management for adolescent by involving various parties, including parent and school, to increase adolescent well-being during Pandemic.

\section{AUTHORS' CONTRIBUTIONS}

Author 1 supervises all the research progress and develops the idea of the research's topic. While author two is made the research topic, collected and analyzed data. And author 3 is a helper for author 1 to discuss the progress of this research while giving an idea for better progress.

\section{ACKNOWLEDGMENTS}

We thank all the participants who have agreed to participate in this study fully. This work was supported by Psychology Department, Medical Faculty, Hasanuddin University. 


\section{REFERENCES}

[1] Laursen, B., \& Hartl, A. C., Understanding loneliness during adolescence: Developmental changes that increase the risk of perceived social isolation, Journal of Adolescence, 2013, 36(6), 1261-1268

[2] Kassin, S., Fein, S., \& Markus, H. R., Social psychology, (9th Ed.), Wadsworth: Cengage Learning, 2013

[3] Goosby, B. J., Bellatorre, A., Walsemann, K. M., \& Cheadle, J. E., Adolescents loneliness and health in early adulthood. Sociol Inq, 2014, 83(4), 1- 22.

[4] Newport Academy, The fact about loneliness in young people, 2020, acces at 3rd February 2021 https://www.newportacademy.com/resources/w ell-being/loneliness-in- young-people/.

[5] Qualter, P., Vanhalts, J., Harris, R., Roekel, E. V., Lodder, G., Bangee, M., Maes, M., \& Verhagen, M., Loneliness across the life span, Perspectives on Psychological Science, 2015, 10(2), 250-264.

[6] Perlman, D., \& Peplau, L. A., Loneliness research: a survey of empirical findings In L. A. Peplau \& S. Goldston (Eds.), Preventing the harmful consequences of severe and persistent loneliness, Government Printing Office, 1984, 13-46.

[7] Griffin, S.C., Williams, A. B., Ravyts, S. G., Mladen, S. N., \& Rybarczyk, B. D., Loneliness and sleep: a systematic review and meta-analysis, Health Psychology Open, 2020, 1-11.

[8] Hawkley, L. C., Preacher, K. J., \& Cacioppo, J. T., Loneliness impairs daytime functioning but not sleep duration, Health Psychology, 2010, 29, 124- 129.

[9] Boylu, A. A., \& Gunay, G., Loneliness and internet addiction among university students, Internet and Technology Addiction, 2019, 109125.

[10] Perdew, L., Internet addiction, Abdo Publishing, 2015.
[11] Alimoradi, Z., Lin, C., Brostrom, A., Bulow, P. H., Bajalan, Z., Griffits, M. D., Ohayon, M. M., \& Pakpour, A. H., Internet addiction and sleep problems: A systematic review and metaanalysis, Sleep Medicine Reviews, 2019, 47, 5161.

[12] Durand, V. M., \& Barlow, D. H., Essentials of abnormal psychology, Wadsworth Cengage Learning, 2013.

[13] Morin, C. M., \& Espie, C. A., Insomnia: a clinical guide to assessment and treatment, Kluwer Academic Publishers, 2004.

[14] Purwanto, S., Anganti, N. N. R., Yahman, S. A., Hirdhania, C. T., Karakteristik gangguan tidur pada usia produktif dan usia pertengahan di kota Surakarta, University Research Colloqium, 2019, 109-120.

[15] Ariani, M. D., Supradewi, R., \& Syafitri, D. U., Peran kesepian dan pengungkapan diri online terhadap kecanduan internet pada remaja akhir, Jurnal Psikologi Proyeksi, 2019, 14(1), 12-21.

[16] Prasojo, R. A., Hasanuddin, M. O., \& Maharani, D. A., Mengujikan internet addiction test ke responden Indonesia, 2018, 1-8.

[17] Clark-Carter, D., Quantitative psychological research: The complete student's companion $\left(4^{\text {th }}\right.$, Ed). Routledge, 2019.

[18] Baron, R. A., Branscombe, N. R., \& Byrne, D., Social psychology (13 th Ed.), Pearson Education, Inc., 2011.

[19] Young, K. S., Internet addiction: symptoms, evaluation, and treatment. Sarasota, Professional Resource Press, 1999.

[20] Fiorillo, A., \& Gorwood, P., The consequences of the COVID-19 pandemic on mental health and implications for clinical practice, European Psychiatry, 2020, 1-4.

[21] Luchetti, M., Lee, J. H., Aschwanden, D., Seskar, A., Strickhouser, J. E., Terracciano, A., \& Sutin, A. R., The trajectory of loneliness in response to COVID-19, American Psychological Association, 2020, 75(7), 1-12. 
[22] Tull, M. T., Edmonds, K. A., Scamaldo, K. M., Richmond, J. R., Rose, J. P., \& Gratz, K. L., Psychological outcomes associated with stay-athome orders and the perceived impact of COVID-19 on daily life, Psychiatry Research, 2020, 200, 1-6.

[23] Sagita, D. D., \& Hermawan, D., Kesepian remaja pada masa pandemi COVID-19, Jurnal Bimbingan Konseling Islam, 2020, 3(2), 122130.

[24] Eyimaya, A. O., \& Irmak, A. Y., Relationship between parenting practices and children's screen time during the COVID-19 pandemic in turkey, Journal of Pediatric Nursing, 2020, 56, 24-29.

[25] Siste, K., Hanafi, E., Sen, L. T., Christian, H., Adrian, Siswidiani, L. P., Limawan, A. P., Murtani, B. J., \& Suwartono, C., The impact of physical distancing and associated factors towards internet addiction among adults in indonesia during COVID-19 pandemic: a nationwide web-based study, Frontiers in Psychiatry, 2020, 11, 1-11.

[26] Fernandes, B., Biswas, U. N., Mansukhani, R. T., Vallejo, A., \& Essau, C. A., The impact of COVID-19 lockdown on internet use and escapism in adolescents, Revista de Psicología Clínica con Niños y Adolescentes, 2020, 7(3), 59-65.

[27] Windiani, I. G. A. T., Noviyani, N. M. R., Adnyana, I. G. A. G. S., Murti, N. L. S. P., \& Soetjiningsih, S., Prevalence of sleep disorders in adolescents and its relation with screen time during the COVID-19 pandemic era, Journal of Medical Sciences, 2021 9, 297-300.

[28] Zhou, S. J., Wang, L. L., Yang, R., Yang, X. J., Zhang, L. G., Guo, Z. C., Chen, J. C., Wang, J. Q., \& Chen, J. X., Sleep problems among chinese adolescents and young adults during the coronavirus-2019 pandemic. Sleep Medicine, 2020, 74, 1-17 